\title{
ANALISIS KORELASI BIAYA CHANGE ORDER TERHADAP BOBOT PEKERJAAN PADA DUA PROYEK JALAN ASPAL PROVINSI BANTEN
}

\author{
Dominicus Edwin ${ }^{1}$ dan Mega Waty ${ }^{2}$ \\ ${ }^{1}$ Program Studi Sarjana Teknik Sipil, Universitas Tarumanagara, Jl. Letjen S. Parman No.1 Jakarta \\ Email: dominicus97@gmail.com \\ ${ }^{2}$ Program Studi Sarjana Teknik Sipil, Universitas Tarumanagara, Jl. Letjen S. Parman No.1 Jakarta \\ Email: mega@ft.untar.ac.id
}

Masuk: 14-01-2020, revisi: 07-02-2020, diterima untuk diterbitkan:19-02-2020

\begin{abstract}
In every project, one thing that often happens is a change order. Change order is a change of work after the contract is signed by the owner and contractor. These changes can occur at the beginning, middle, or in construction projects. To minimize change orders, a change order correlation analysis can be done using the original data, with the parameters change order ratio in addition (CORA) and change order ratio in substraction $(C O R S)$. The data used in this study uses two original change order contract data on projects in Banten Province. This study produced 4 correlation results obtained from Pearson correlation in the SPSS program. The results of the correlation of the weight of each work to CORA on project 1 did not show any correlation. The results of the correlation of weights for each work with CORA project 2 and the results of the correlation of weights with CORS project 2 showed a significant correlation at the 95\% degree of confidence. The results of the correlation of the weight of each work with CORS project 1 showed a very significant correlation at the $99 \%$ degree of confidence.
\end{abstract}

Keywords: Change orders, contracts, correlations, flexible pavement

\begin{abstract}
ABSTRAK
Dalam setiap proyek, salah satu hal yang sering terjadi ialah change order. Change order adalah perubahan pekerjaan setelah kontrak yang ditandatangani oleh pemilik dan kontraktor. Perubahan itu dapat terjadi pada awal, tengah, ataupun pada dalam proyek konstruksi. Untuk meminimalisir change order maka dapat dilakukan analisis korelasi change order menggunakan data asli, dengan parameter change order ratio in addition (CORA) dan change order ratio in substraction (CORS). Data yang digunakan pada studi ini menggunakan dua data asli kontrak change order pada proyek konstruksi jalan aspal di Provinsi Banten. Baik data proyek 1 maupun data proyek 2 memiliki data kontrak change order biaya awal dan data biaya setelah terjadinya change order. Studi ini menghasilkan 4 hasil korelasi yang di dapat dari korelasi pearson pada program SPSS. Hasil korelasi bobot tiap pekerjaan terhadap CORA pada proyek 1 tidak menunjukan adanya korelasi. Hasil korelasi bobot tiap pekerjaan dengan CORA proyek 2 dan hasil korelasi bobot dengan CORS proyek 2 menunjukan adanya korelasi yang signifikan pada tingkat derajat kepercayaan 95\%. Hasil korelasi bobot tiap pekerjaan dengan CORS proyek 1 menunjukan adanya korelasi yang sangat signifikan pada tingkat derajat kepercayaan $99 \%$.
\end{abstract}

Kata kunci: change order, kontrak, korelasi, jalan aspal

\section{PENDAHULUAN}

\section{Latar Belakang}

Perkembangan proyek konstruksi di Indonesia masih sangat berkembang pesat, hal ini di karenakan negara Indonesia yang masih termasuk dalam negara berkembang, sehingga pembangunan harus terus di kembangkan. Pada proyek di Indonesia banyak sekali macam-macam proyek konstruksi yang dilakukan baik gedung, jembatan, jalan raya dan lain-lain. Seiring berjalannya waktu perkembengan proyek konstruksi terus berkembang pesat hal ini dapat kita lihat dari proyek konstruksi yang hasilnya sangat beragam. Tidak hanya proyeknya tetapi strukturnya pun terus diperbarui agar nyaman, efisien, dan aman.Salah satu tahap pekerjaan yang di lakukan dalam membangun suatu proyek konstruksi adalah perencanaan, perencana merencanakan bangunan dengan berbagai perhitungan dan metode disetiap desainnya, kemudian dilanjutkan dengan pelakasanaan pembangunan dengan gambar kerja menjadi detail dalam pembangunan, dan pengawasan yang mengawasi proses pelaksanaan agar dalam proses pembangunan 
sesuai dengan spesifikasi yang telah ditentukan.Dalam setiap proyek, hal yang sering terjadi ialah change order. Change order adalah perubahan pekerjaan setelah kontrak ditandatangani oleh pemilik dan kontraktor. Perubahan itu dapat terjadi pada awal, tengah, ataupun pada dalam proyek konstruksi. Hampir seluruh proyek yang ada, baik proyek pemerintah maupun proyek swasta akan mengalami change order, yang terjadi atas permintaan kontraktor ataupun pemilik (Waty, 2013). Penulis memfokuskan pada analisis persentase change order di provinsi Banten. Data yang dipakai merupakan data asli proyek konstruksi jalan aspal di provinsi Banten, maka dengan data tersebut akan diketahui persentase change order yang terjadi pada proyek konstruksi jalan aspal (flexible pavement). Setelah itu akan di bandingkan pada jenis pekerjaan apakah yang mengalami change order baik dengan nilai persentase terendah, maupun dengan nilai tertinggi.

Batasan-batasan masalah yang di gunakan dalam skripsi ini ialah sebagai berikut:

1. Hanya menghitung persentase change order di provinsi Banten.

2. Hanya menggunakan data proyek konstruksi perkerasan jalan aspal (flexible pavement) di provinsi Banten.

3. Parameter yang digunakan adalah Change Order Ratio (COR), Change Order Ratio in Addition (CORA), Change Order Ratio in Substraction (CORS).

4. Hanya menggunakan data proyek konstruksi yang telah selesai.

5. Hanya menggunakan data proyek konstruksi jalan aspal (flexible pavement) tahun 2017, 2018 dan 2019.

Rumusan masalah yang akan di bahasa dalam skripi ini adalah:

1. Berapa dan pada jenis pekerjaan apakah change order terbesar dan terendah pada proyek konstruksi jalan aspal (flexible pavement) di provinsi Banten?

2. Bagaimana hubungan korelasi antara change order in addition (CORA) dan change order in substraction (CORS) dengan bobot tiap pekerjaan?

Tujuan penelitian skripsi ini adalah untuk menjawab pertanyaan dari rumusan masalah tersebut, yaitu sebagai berikut:

1. Mengetahui besar dan pada jenis pekerjaan mana yang memiliki persentase change order terbesar dan terendah pada proyek konstruksi jalan aspal (flexible pavement) di provinsi Banten.

2. Mengetahui hubungan korelasi antara change order in addition (CORA) dan change order in substraction (CORS) dengan bobot tiap pekerjaan.

\section{Change Order}

Change order adalah persetujuan tertulis untuk memodifikasi, menambah, atau memberi alternatif pada pekerjaan yang telah diatur dalam dokumen kontrak antara pemilik dan kontraktor. Perubahan tersebut dapat dipertimbangkan untuk masuk dalam ruang lingkup proyek yang asli, dan merupakan satu satunya cara yang sah. Change order terjadi apabila ada penambahan, pengurangan, atau perubahan di dalam suatu pekerjaan yang diajukan oleh kontraktor, yang semuanya di ajukan secara tertulis (Sulistio \& Waty, 2008). Change order terjadi apabila ada penambahan, pengurangan, atau perubahan di dalam suatu pekerjaan yang diajukan oleh kontraktor, yang semuanya di ajukan secara tertulis (Clough dan Sears, 1994).

\section{Tipe Perubahan}

Terdapat dua tipe perubahan pada change order, yaitu:

\section{Perubahan Informal (constructive changes)}

Constructive changes adalah tindakan informal dalam mengesahkan suatu modifikasi di lapangan yang terjadi karena kesalahan bertindak. Perubahan informal (constructive changes), atau disebut juga perubahan konstruktif menunjukan perubahan lingkup pekerjaan kontraktor atau metode pelaksanaan akibat kesalahan pemilik, pihak ketiga seperti kontraktor dan juga penyuplai, serta seluruh kesalahan di luar kontraktor.persetujuan tertulis untuk memodifikasi, menambah, atau memberi alternatif pada pekerjaan yang telah diatur dalam dokumen kontrak antara pemilik dan kontraktor. Perubahan tersebut dapat dipertimbangkan untuk masuk dalam ruang lingkup proyek yang asli, dan merupakan satu satunya cara yang sah. Change order terjadi apabila ada penambahan, pengurangan, atau perubahan di dalam suatu pekerjaan yang diajukan oleh kontraktor, yang semuanya di ajukan secara tertulis

\section{Perubahan Formal}

Perubahan formal diajukan dalam bentuk tertulis, yang diusulkan oleh pemilik dan ditujukan kepada kontraktor untuk mengubah lingkup kerja, waktu pelaksanaan, biaya-biaya atau hal-hal lain yang berbeda yang telah 
dispesifikasikan dalam kontrak. Perubahan formal biasanya menyangkut alternatif-alternatif pada desain suatu konstruksi dan diwujudkan dalam bentuk perbaikan-perbaikan dalam gambar atau spesifikasi konstruksi. Pemilik seringkali mengubah keperluannya atau mengubah kontrak kerja atau supplier

\section{Penyebab Change Order}

Menurut Finke (1998), penyebab change order adalah sebagai berikut:

1. Pengalihan sumber daya atau keahlian pekerja yang kurang;

2. Pemogokan yang terjadi pada area pekerjaan;

3. Meningkatnya harga pasar;

4. Lemahnya pengawasan;

5. Penghentian sementara pekerjaan yang sedang berlangsung;

6. Penundaan waktu.

\section{Indikator Change Order}

Terdapat tiga perhitungan yang dipakai dalam mengukur chang order yang terjadi. Indikator untuk menghitung margin biaya change order, yakni COR, CORA, dan CORS. Ketiga indikator tersebut dijelaskan sebagai berikut (Hsieh, et al., 2004):

1. Change Order Ratio (COR)

Indeks ini mengukur dari total biaya varian dari proyek yang terjadi change order.

$\mathrm{COR}=$ (jumlah dari nilai tambah dan kurang untuk proyek yang dilakukan change order / harga kontrak asal) $\mathrm{x}$ $100 \%$

2. Change Order ratio in Addidtion (CORA)

Indeks ini mengukur rasio dari total tambah pada proyek yang mengalami change order.

CORA = (jumlah dari nilai tambah dari proyek yang mengalami change order / harga kontrak asal) $\mathrm{x} 100 \%$

3. Change Order Ratio in Substraction (CORS)

Indeks ini mengukur rasio dari total substraksi yang dicapai pada proyek yang dilakukan change order.

CORS = (jumlah dari nilai pekerjaan kurang dari proyek yang dilakukan change order / harga kontrak asal) $\mathrm{x} 100 \%$

\section{METODE PENELITIAN}

\section{Langkah Penelitian}

Dalam penelitian ini dilakukan langkah-langkah sebagai berikut:

1. Mencari dan mengumpulkan data change order dari proyek perkerasan jalan aspal (flexible pavement) di provinsi Banten.

2. Mengolah data untuk perhitungan change order agar dapat mengetahui besarnya change order di tiap proyek di Banten berdasarkan data yang telah di peroleh

3. Menentukan jenis pekerjaan manakah pada proyek jalan aspal (flexible pavement) yang mengalami change order teringgi dan terendah

4. Menarik kesimpulan dan saran dari hasil analisis.

\section{Pengumpulan Data}

Pada skripsi ini data yang di gunakan adalah data sekunder, yakni di dapatkan dari data change order asli pada proyek perkerasan jalan aspal (flexible pavement) di provinsi Banten. Data yang di kumpulkan berupa data kontrak change order sebelum perubahan dah setelah terjadinya change order. Data yang digunakan sebanyak 2 buah data proyek yang di beri nama proyek 1 dan proyek 2 .

\section{Pengolahan Data}

Dalam proses pengolahan data ini, data-data change order yang telah dikumpulkan akan diolah dan di catat ke dalam microsoft excel. Data tersebut akan di olah menggunakan rumus-rumus indicator change order (COR,CORA, dan CORS), lalu di korelasikan terhadap bobot tiap pekerjaan.

\section{HASIL ANALISA DAN PEMBAHASAN}

Perhitungan COR tiap proyek: 
Tabel 1 Hasil Perhitungan COR Proyek 1

URAIAN PEKERJAAN

COR (\%)

DIVISI 1. - MOBILISASI

\begin{tabular}{|c|c|}
\hline Mobilisasi & 0.0000 \\
\hline Manajemen dan Keselamatan Lalu Lintas & 0.0000 \\
\hline Pengamanan Lingkungan Hidup & 0.0000 \\
\hline Manajemen Mutu & 0.0000 \\
\hline \multicolumn{2}{|l|}{ DIVISI 2. DRAINASE } \\
\hline Galian untuk Selokan Drainase dan Saluran Air & -0.0905 \\
\hline Pasangan Batu dengan Mortar & -2.0879 \\
\hline Gorong-gorong Pipa Beton Bertulang diameter dalam $95-105 \mathrm{~cm}$ & -0.0369 \\
\hline Saluran berbentuk U Tipe DS 3 & 0.3047 \\
\hline \multicolumn{2}{|l|}{ DIVISI 3. PEKERJAAN TANAH } \\
\hline Galian Biasa & 0.4063 \\
\hline Galian Perkerasan Beraspal tanpa Cold Milling Machine & -0.5652 \\
\hline Galian Perkerasan Berbutir & 1.2554 \\
\hline Galian Perkerasan Beton & -1.5812 \\
\hline Timbunan Pilihan dari sumber galian & 0.7362 \\
\hline \multicolumn{2}{|l|}{ DIVISI 4. PELEBARAN PERKERASAN DAN BAHU JALAN } \\
\hline Lapis Pondasi Agregat Kelas S & 1.5164 \\
\hline
\end{tabular}

DIVISI 5. PERKERASAN ASPAL

Lapis Resap Pengikat - Aspal Cair $\quad 0.0443$

Lapis Perekat - Aspal Cair $\quad-0.0655$

\begin{tabular}{lc} 
Laston Lapis Aus (AC-WC) & 0.2418 \\
\hline
\end{tabular}

\begin{tabular}{ll} 
Laston Lapis Aus Perata (AC-WC(L)) & 1.7079 \\
\hline
\end{tabular}

Laston Lapis Antara (AC-BC) 2.0373

Laston Lapis Antara Perata (AC-BC/L) 0.7153

Bahan Anti Pengelupasan $\quad-0.0810$

DIVISI 6. PENGEMBALIAN KONDISI DAN PEK. MINOR

Lapis Pondasi Agregat Kelas A untuk Pekerjaan Minor $\quad-0.0683$

Campuran Aspal Panas untuk Pekerjaan Minor $\quad-0.0203$

\begin{tabular}{lr}
\hline Pohon Jenis.................. & -0.0361 \\
\hline
\end{tabular}

\begin{tabular}{lc} 
Marka Jalan Termoplastik & 0.0205 \\
\hline
\end{tabular}


Rambu Jalan dengan Permukaan Pemantul Engineer Grade 0.0000

Patok Kilometer

Kerb Pracetak Jenis 2 (Penghalang/ Barrier) $-0.0081$

Perkerasan Blok Beton pada Trotoar dan Median $-0.1216$

Tabel 2 Hasil Perhitungan COR Proyek 2

\begin{tabular}{lc}
\hline RINCIAN ITEM PEKERJAAN & COR (\%) \\
\hline BAB 1 UMUM & \\
\hline Mobilisasi & 0.0000 \\
\hline Manajemen dan Keselamatan Lalu-lintas & 0.0000 \\
\hline Pengeboran, termasuk SPT dan Laporan & 0.0814 \\
\hline
\end{tabular}

\begin{tabular}{ll} 
Manajemen Mutu & 0.0000 \\
\hline
\end{tabular}

BAB 2 DRAINASE

$\begin{array}{ll}\text { Galian untuk Selokan Drainase dan Saluran Air } & 0.1174\end{array}$

\begin{tabular}{ll}
\hline Pasangan Batu Dengan Mortar & 0.6858 \\
\hline
\end{tabular}

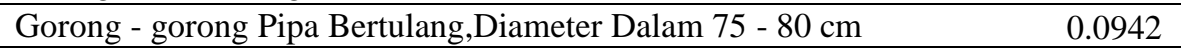

Saluran berbentuk U Tipe DS 1 (60x80) cm /HD \& Tutup Saluran 0.9926

Saluran berbentuk U Tipe DS $3(20 \times 30) \mathrm{cm}$ (Tali Air) + Tutup

Saluran

Beton K250 (fc' 20) untuk struktur drainase beton minor $\quad 0.0613$

Baja Tulangan untuk struktur drainase beton minor

\begin{tabular}{lr} 
Bahan Porous untuk Bahan Penyaring (Filter) & -0.0418 \\
\hline
\end{tabular}

\begin{tabular}{lr} 
Anyaman Filter Plastik & 0.0094 \\
\hline
\end{tabular}

\begin{tabular}{ll} 
Kuras Saluran & 0.0000 \\
\hline
\end{tabular}

BAB 3 PEKERJAAN TANAH

$\begin{array}{ll}\text { Galian Biasa } & 0.0892\end{array}$

Galian Perkerasan Beraspal dengan Cold Milling Machine $\quad 1.2690$

Galian Perkerasan Beraspal tanpa Cold Milling Machine $\quad 0.0977$

\begin{tabular}{ll} 
Galian Perkerasan Berbutir & 0.0725 \\
\hline
\end{tabular}

$\begin{array}{ll}\text { Galian Perkerasan Beton } & 0.3619\end{array}$

\begin{tabular}{ll} 
Timbunan Pilihan dari sumber galian & 0.0595 \\
\hline
\end{tabular}

Timbunan Biasa dari Galian $\quad 0.0122$

Penyiapan Badan Jalan

\begin{tabular}{ll} 
Pembersihan dan Pengupasan Lahan & 0.0587 \\
\hline
\end{tabular}

BAB 4 PEKERJAAN ASPAL

Lapis Resap Pengikat - Aspal Cair

Lapis Perekat - Aspal Cair

Laston Lapis Aus (AC-WC)

Laston Lapis Aus Perata (AC-WC(L)) $\quad-0.1203$

Laston Lapis Antara (AC-BC) 1.5008

$\begin{array}{ll}\text { Bahan anti pengelupasan } & 0.0393\end{array}$

BAB 5 PENGEMBALIAN KONDISI DAN PEKERJAAN

MINOR

\begin{tabular}{lc}
\hline Marka Jalan Termoplastik & 0.0000 \\
\hline Kerb Pracetak Jenis 1 (Peninggi/Mountable) & 0.0000 \\
\hline Kerb Pracetak Jenis 6 (Kerb dengan Bukaan) & 0.0000 \\
\hline BAB 6 PEKERJAAN HARIAN & 0.0000 \\
\hline Mandor & 0.0000 \\
\hline Pekerja Biasa & 0.0000 \\
\hline Tukang Kayu, Tukang Batu, dsb &
\end{tabular}




\begin{tabular}{ll}
\hline Dump Truck, kapasitas $3-4 \mathrm{~m}^{3}$ & 0.0000 \\
\hline Mesin Pengaduk Beton (Molen) 0,3 - 0,6 M3 & 0.0000 \\
\hline Jack Hammer & 0.0000 \\
\hline BAB 7 PEKERJAAN PEMELIHARAAN RUTIN & 0.0000 \\
\hline Pemeliharaan Rutin Perkerasan & 0.0000 \\
\hline Pemeliharaan Rutin Bahu Jalan & 0.0000 \\
\hline Pemeliharaan Rutin Selokan, Saluran Air, Galian dan Timbunan & 0.0000 \\
\hline Pemeliharaan Rutin Perlengkapan Jalan & \\
\hline BAB 8 PEMELIHARAAN KINERJA JALAN & 0.0000 \\
\hline Pasangan Batu dengan Mortar & 0.0000 \\
\hline Lapis Pondasi Agregat Kelas S & 0.0000 \\
\hline Campuran Aspal Panas & 0.0000 \\
\hline Pengecatan Kerb dan Median & 0.0000 \\
\hline Pengendalian Tanaman & 0.0000 \\
\hline Pembersihan Drainase &
\end{tabular}

Hasil korelasi antara bobot dengan CORA dan CORS:

Tabel 3 Hasil korelasi bobot dengan CORA proyek 1

Correlations

\begin{tabular}{llrr}
\hline & & Bobot Pekerjaan & \multicolumn{1}{c}{ CORA } \\
\hline Bobot Pekerjaan & Pearson Correlation & 1 & .025 \\
\cline { 2 - 4 } & Sig. (2-tailed) & 11 & .942 \\
\cline { 2 - 4 } & $\mathrm{N}$ & .025 & 11 \\
\hline \multirow{2}{*}{ CORA } & Pearson Correlation & .942 & \\
\cline { 2 - 4 } & Sig. (2-tailed) & 11 & 11 \\
\cline { 2 - 4 } & $\mathrm{N}$ & & \\
\hline
\end{tabular}

Hasil korelasi bobot tiap pekerjaan dengan CORA proyek 1 menunjukkan nilai signifikansi antara bobot dengan CORA sebesar 0.942 yang lebih besar dari 0.05, maka dapat disimpulkan bahwa tidak terdapat kolerasi antara variabel bobot tiap pekerjaan dengan variabel CORA pada proyek 1. Dalam analisis kolerasi ini juga menunjukkan hasil pearson yang bernilai 0.025 , yang berarti semakin tinggi nilai bobot tiap pekerjaan, semakin tinggi pula nilai CORA yang terjadi. Besarnya kolerasi pearson dibawah 0.5 yang menunjukan kolerasi yang lemah antara bobot tiap pekerjaan dengan nilai CORA pada proyek 1. Data yang digunakan pada korelasi ini iyalah sebanyak 11 data yang mengalami persentase pertambahan biaya change order (CORA) pada proyek 1.

Tabel 4 Hasil korelasi bobot dengan CORA proyek 2

Correlations

\begin{tabular}{|c|c|c|c|}
\hline & & Bobot Pekerjaan & CORA \\
\hline \multirow[t]{3}{*}{ Bobot Pekerjaan } & Pearson Correlation & 1 & $.742^{*}$ \\
\hline & Sig. (2-tailed) & & .022 \\
\hline & $\mathrm{N}$ & 9 & 9 \\
\hline \multirow[t]{3}{*}{ CORA } & Pearson Correlation & $.742^{*}$ & 1 \\
\hline & Sig. (2-tailed) & .022 & \\
\hline & $\mathrm{N}$ & 9 & 9 \\
\hline
\end{tabular}

*. Correlation is significant at the 0.05 level (2-tailed). 
Hasil korelasi bobot tiap pekerjaan dengan CORA menunjukkan nilai signifikansi antara bobot dengan CORA sebesar 0.022 yang lebih kecil dari 0.05, yang dapat disimpulkan bahwa terdapat kolerasi yang signifikan antara variabel bobot tiap pekerjaan dengan variabel CORA pada proyek 2. Dalam analisis kolerasi ini juga menunjukkan hasil pearson yang bernilai 0.742 , yang berarti semakin tinggi nilai bobot tiap pekerjaan, semakin tinggi pula nilai CORA yang terjadi. Besarnya kolerasi pearson diatas 0.5 yang menunjukan kolerasi yang kuat antara bobot tiap pekerjaan dengan nilai CORA pada proyek 2. Data yang digunakan pada korelasi ini iyalah sebanyak 9 data yang mengalami persentase pertambahan biaya change order (CORA) pada proyek 2.

Tabel 5 Hasil korelasi bobot dengan CORS proyek 1

\begin{tabular}{llrr}
\hline \multicolumn{3}{c}{ Correlations } \\
\hline \multirow{2}{*}{ Bobot Pekerjaan } & \multicolumn{2}{c}{ Bobot Pekerjaan } & \multicolumn{1}{c}{ CORS } \\
\cline { 2 - 4 } & \multicolumn{1}{l}{ Pearson Correlation } & 1 & $-.969^{* *}$ \\
\cline { 2 - 4 } & Sig. (2-tailed) & 13 & .000 \\
\cline { 2 - 4 } & $\mathrm{N}$ & $-.969^{* *}$ & 13 \\
\hline \multirow{2}{*}{ CORS } & Pearson Correlation & .000 & 13 \\
\cline { 2 - 4 } & Sig. (2-tailed) & 13 & 13 \\
\cline { 2 - 4 } & $\mathrm{N}$ & & \\
\hline$* *$ Correlation is significant at the 0.01 level (2-tailed).
\end{tabular}

Hasil korelasi bobot tiap pekerjaan dengan CORS menunjukkan nilai signifikansi antara bobot dengan CORS sebesar 0.000 yang lebih kecil dari 0.05 , yang dapat disimpulkan bahwa terdapat kolerasi yang signifikan antara variabel bobot tiap pekerjaan dengan variabel CORA pada proyek 1. Dalam analisis kolerasi ini juga menunjukkan hasil pearson yang bernilai -0.969 , yang berarti semakin tinggi nilai bobot tiap pekerjaan, semakin tinggi pula nilai CORA yang terjadi. Besarnya kolerasi pearson diatas 0.5 yang menunjukan kolerasi yang kuat antara bobot tiap pekerjaan dengan nilai CORA pada proyek 1. Data yang digunakan pada korelasi ini iyalah sebanyak 13 data yang mengalami persentase pertambahan biaya change order (CORS) pada proyek 1.

Tabel 6 Hasil korelasi bobot dengan CORS proyek 2

\begin{tabular}{|c|c|c|c|}
\hline \multicolumn{4}{|c|}{ Correlations } \\
\hline & & Bobot Pekerjaan & CORS \\
\hline \multirow[t]{3}{*}{ Bobot Pekerjaan } & Pearson Correlation & 1 & $-.974^{*}$ \\
\hline & Sig. (2-tailed) & & .026 \\
\hline & $\mathrm{N}$ & 4 & 4 \\
\hline \multirow[t]{3}{*}{ CORS } & Pearson Correlation & $-.974^{*}$ & 1 \\
\hline & Sig. (2-tailed) & .026 & \\
\hline & $\mathrm{N}$ & 4 & 4 \\
\hline
\end{tabular}

Hasil korelasi bobot tiap pekerjaan dengan CORS menunjukkan nilai signifikansi antara bobot dengan CORS sebesar 0.026 yang lebih kecil dari 0.05 , yang dapat disimpulkan bahwa terdapat kolerasi yang signifikan antara variabel bobot tiap pekerjaan dengan variabel CORA pada proyek 2. Dalam analisis kolerasi ini juga menunjukkan hasil pearson yang bernilai -0.974 , yang berarti semakin tinggi nilai bobot tiap pekerjaan, semakin tinggi pula nilai CORA yang terjadi. Besarnya kolerasi pearson diatas 0.5 yang menunjukan kolerasi yang kuat antara bobot tiap pekerjaan dengan nilai CORA pada proyek 2. Data yang digunakan pada korelasi ini iyalah sebanyak 4 data yang mengalami persentase pertambahan biaya change order (CORS) pada proyek 2.

\section{KESIMPULAN}

Berdasarkan analisis data change order yang telah dilakukan menggunakan rumus change order (COR) maka dapat disimpulakan bahwa: 
1. Persentase dan jenis pekerjaan change order paling besar dan terendah, yaitu:

1.1 Persentase dan jenis pekerjaan change order paling besar terdapat pada proyek 2, yaitu sebesar $2.48 \%$ yakni terdapat pada pekerjaan laston lapis aus (Asphalt Concrete Wearing Course).

1.2 Persentase dan jenis pekerjaan change order paling rendah terdapat pada proyek 2, yaitu sebesar $0.012 \%$ yakni terdapat pada pekerjaan timbunan biasa dari galian.

2. Hasil hubungan korelasi antara bobot tiap pekerjaan dengan change order ratio in addition (CORA) dan change order ratio in substraction (CORS), yaitu:

2.1 Hasil korelasi antara bobot tiap pekerjaan dengan change order ratio in addition (CORA) pada proyek 1 menunjukan tidak ada korelasi antara bobot pekerjaan dengan change order rasio in addition (CORA)

2.2 Hasil korelasi antara bobot tiap pekerjaan dengan change order ratio in addition (CORA) pada proyek 2 menunjukan adanya korelasi yang signifikan pada tingkat $5 \%$

2.3 Hasil korelasi antara bobot tiap pekerjaan dengan change order ratio in substraction (CORS) pada proyek 1 menunjukan adanya korelasi yang lebih signifikan pada tingkat $1 \%$

2.4 Hasil korelasi antara bobot tiap pekerjaan dengan change order ratio in substraction (CORS) pada proyek 2 menunjukan adanya korelasi yang signifikan pada tingkat 5\%

\section{DAFTAR PUSTAKA}

Clough, Richard H and Glenn A Sears. Construction Contracting (6th ed.). New York: John Wiley \& Sons.Inc, 1994.

Finke, Michael R. "A Better Way to Estimate and Mitigate Disruption.” Journal of Construction Engineering and Management 1998: 124,490-497.

Hsieh, Ting-ya, Shih-tong Lu and Cho-hui Wu. "Statistical Analysis of Causes for Change Order in Metropolitan Public Works International.” Journal of Project Management 2004: 22,679-686.

Sulistio, Hendrik and Mega Waty. "Analysis and Evaluation Change Order in Flexible Pavement." Media Komunikasi Teknik Sipil 2007.

Waty, Mega. Analisa Change Order pada Proyek Perkerasaan Jalan. Bandung: STEMBI-Bandung Business School, 2013. 